\title{
The Future for Electronic Business Systems
}

\author{
Retailers and consumers are reluctant to use electronic devices \\ in the home to arrange for exchange of goods and services, but \\ the electronic transfer of funds is gaining wide acceptance.
}

CLAUDE R. MARTIN, JR.

The author is a faculty member in the Graduate School of Business Administration at the University of Michigan.

Major changes are occurring in the manner in which goods and services are delivered to consumers and to industry, as systems of electronic interchange are developed. Retailers, bankers, consumers, communicators, and those charged with regulating innovative exchange processes are becoming increasingly interested in understanding the effects of such technological changes.

Under the auspices of Project CABLE (funded by the National Science Foundation) at the University of Michigan, more than 250 in-depth interviews with executives of major financial and retailing institutions were conducted, and current literature was reviewed, in an effort to evaluate the use, acceptance, and impact of new mediums of exchange. The research concentrated on two types of electronic interchange between buyer and seller: teleshopping for goods and electronic transfer of funds. ${ }^{1}$

\section{TELESHOPPING}

Teleshopping refers to the purchase of goods from a retailer using a remote electronic device in the home. A number of indicators are available which show the potential for this kind of shopping. The Business Planning Group of Bell Canada employed a modified Delphi approach to solicit the opinions and expectations of a limited group of housewives and experts in the field of communications research towards this method of purchase. ${ }^{2}$ The study showed consumers are receptive to the use of telecommunication in marketing goods.

The rapid growth in retail catalog sales by Sears, Roebuck and Co., Montgomery Ward \& Co., Inc., and J.C. Penney Company, Inc., seems to indicate consumer willingness to shop by remote means, away from the traditional retail store environment. Sears also participated in an experiment involving 2,000 households in Toronto, Canada, to test the feasibility of an in-home, electronic ordering system. This research by Simpson-Sears, Ltd., and IBM of Caniada, Ltd., found that consumer reaction was positive and the technological "bugs" were solvable. However, retailers are concerned that if customers become too used to in-home shopping, net total sales and physical plant investment may suffer serious negative ramifications.

1. Kan Chen, "Policy Research in Cable Communication: Project CABLE Final Report," University Program in Telecommunications Research (Ann Arbor: University of Michigan, 1975).

2. Michael T. Bedford, "The Future of Communications Service for the Home," a study prepared by the Business Planning Group of the Bell Canada Company, 1972. 


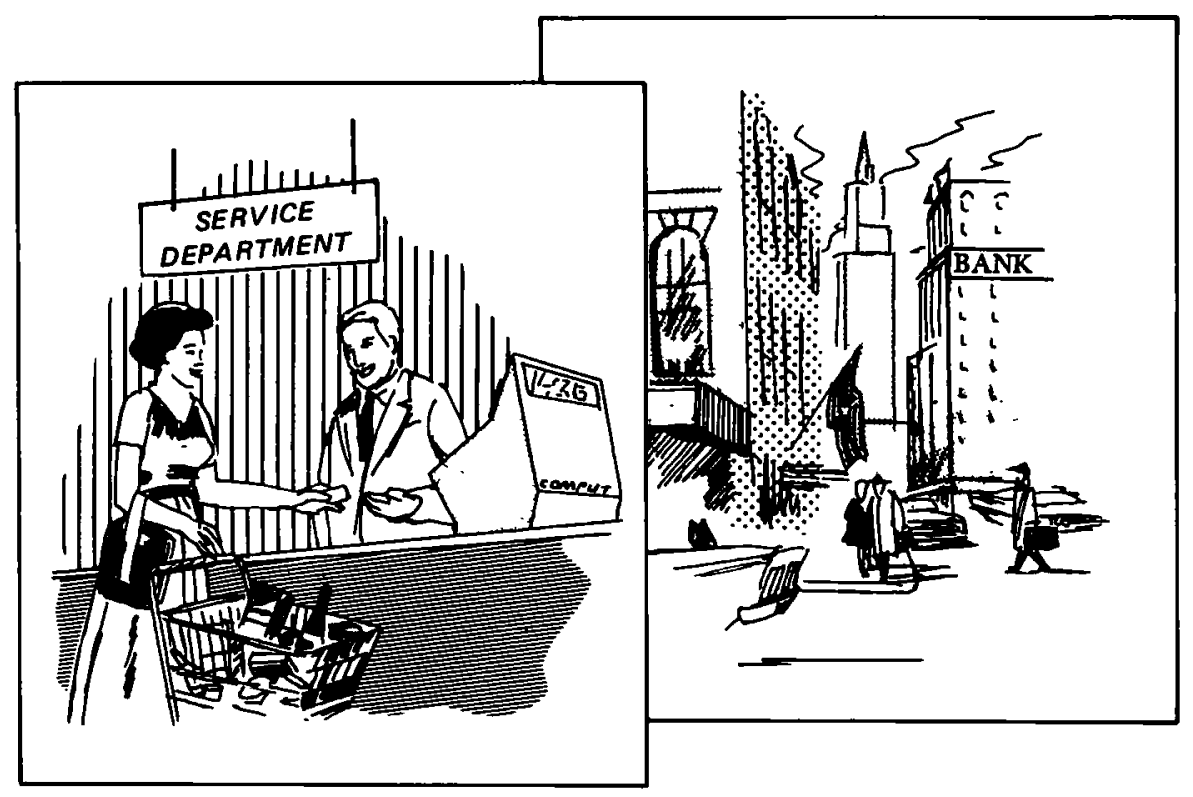

"The consumer comes to a retailer for the purchase of goods and/or services and instead of presenting cash or a check for payment, he uses a debit card. The card is fed into the point-of-sale device for processing, and a specified amount of money is electronically transferred from the customer's account to that of the retailer."
There have been several experiments in selling goods via cable television systems. number of products, most of which would be classified as impulse goods. The stimuli for purchase in these experiments has generally been advertising on the cable system itself, thus limiting the purchasing stimuli and disallowing self-activated consumer purchases.

The development of the "total system" cash register and the use of electronic sensing devices at store checkouts can be regarded as an evolutionary step that will facilitate in-home shopping. Once an internal system handles transactions such as inventory control, payroll, accounts receivable and credit clearances (as do the new Sears, Wards, and Penney systems), and the group that interacts with it is expanded to all employees, the logical extension is to have more persons directly connect into the system (the customer).

Much of the research effort to date has been devoted to studying the delivery system, but that is not the key to understanding the problems and eventual construct of telecommunication exchange. A retailer must

undertake a major reordering of his internal systems if he is to have his customers interacting directly with that system. Also, consumer behavior must be examined to determine what goods and services might be bought via remote means. What effect will communicating with computers instead of other humans have on fulfillment of social needs? The Project CABLE research showed a lack of research into these critical elements.

Overall, teleshopping is a concept removed from most retailers' strategic planning. The more than fifty retailers interviewed in Project CABLE were generally intrigued, but not enthusiastic about the prospects of a new system that might void their large capital commitments.

\section{ELECTRONIC FUNDS TRANSFER}

Quite the opposite is true of an electronic funds transfer system (EFTS). The most simplistic description of EFTS is that it is a system for exchanging value via electronic entry, without processing paper. Basically it is nothing more than an exchange of informa- 
tion between consumers, retailers, and financial institutions. The linkages in this information processing system are principally regular or leased telephone lines. However, specialized communications carriers are being developed that offer competition on the basis of cost, security, and speed of data transmission.

Within a fully developed EFTS, two major devices allow consumers to interact with the retail and financial institutions. These are the point-of-sale (POS) terminal and the automatic teller machine (ATM).

POS devices range from a regular telephone for verbal checking of account status to high speed electronic cash registers, misnamed because in reality they are data processing terminals for the retailer's total system. The consumer comes to a retailer for the purchase of goods and/or services and instead of presenting cash or a check for payment, he uses a debit card. The card is fed into the POS device for processing, and a specified amount of money is electronically transferred from the customer's account to that of the retailer.

The ATM is a refinement of devices that banks have been placing on the outside walls of their offices for several years. The early machines did nothing more than dispense cash, usually within narrow limits, and accepted deposits, particularly during nonbanking hours. However, technological refinement and on-line communication links now allow these devices to handle $80 \%$ of the functions normally performed by regular bank tellers. With clearance of legal restrictions, these devices can be placed away from the financial institutions' premises, and offer services in diverse locations at a relatively low capital cost to the bank or thrift institution.

The Project CABLE research indicated we are headed toward a future nationwide EFTS. In fact, the component parts of such a system are, or can be, technically implemented today. However, the fundamental question is. the timing and nature of this evolution.

\section{Consumer Acceptance}

Consumer acceptance of electronic funds transfer systems involves the classic question of consumer readiness for change. The previously-cited Bell of Canada study, because of its modified Delphi approach, allowed for the education of respondents before eliciting an ultimate assessment of the potential for remote banking services. The research interviews conducted in Project CABLE showed the difficulty of measuring reactions towards funds transfer systems without first giving the respondents detailed briefings of their technical potential. The Bell Canada study showed that over $80 \%$ of the participants expected that checkless banking service, once developed, would be used for transactions involving retail stores, transportation tickets, contractual payments, and utility payments. The participants also expected costs for the service to remain about the same as those for conventional banking transactions.

In August 1973 the Survey Research Center of the University of Michigan queried 1,265 persons about their attitudes toward savings accounts, new forms of money transfers, and their practices regarding savings. The study was not aimed solely at testing the potential for electronic funds transfer systems and it did not contain preliminary information about technical possibilities of such systems before eliciting responses. Perhaps because of these factors, questions associated with consumer readiness for electronic funds transfer elicited predominantly negative responses. $^{3}$

3. Summary Report: Study of Savings and Money Handling (University of Michigan: Survey Research Center, Aug. 1974). 
The Bank Marketing Association commissioned two qualitative studies that dealt with EFTS. Among the major relevant findings were:

As is the case with many types of innovations, acceptance by the public comes in stages. Among the first to accept innovations are the young and professional/managerial class... and the elderly being among the last to use this equipment.

A general attitude exists among all groups of people we studied that automation has become a way of life ... there appears to be widespread acceptance of its inevitableness... many individuals are able to envision the day when widespread networks of automated banking equipment will expedite their banking transactions-both near and away from home.

While access to proprietary studies conducted by retailing and financial institutions has been difficult, Cynthia Miller of First National City Bank of New York touched on that organization's EFTS research at a recent conference. $^{5}$ Ms. Miller reported that any EFTS must satisfy consumer needs and that implementation of such a system requires substantive changes in consumer behavior. She identified three types of resistance to electronic funds transfer systems: general resistance to change, fear of technology, and lack of confidence in computers. First National City Bank of New York is therefore attempting to prepare consumers gradually for change, with the ultimate goal being to have debit cards replace both checks and cash, and to have retail outlets become sales and service facilities for the bank. Data on automatic teller machines that have been gathered by financial institutions across the country generally indicate that the consumer will accept those services "that substantially increase his convenience or substantially lower his costs, and do not introduce substantial negatives."

4. Sidney Levy and Shirley Greene, 1972 Research Report: Man's Interface with the Money Machine (Chicago: Bank Marketing Association, 1972), pp. I-II.

5. Cynthia Miller, "Marketing EFTS to the Consumer," an address to the 1975 EFTS Conference, Feb. 11, 1975, Atlanta, $\mathrm{Ga}$.

6. EFTS Value Analysis, Research Project No. 5, Payment Systems Research Program (New York: December 1974), pp. II-14.
The major data concerning consumer acceptance of point-of-sale electronic funds transfer systems have come from a series of actual experiments across the country, most notable of which is the "Hinky-Dinky" experiment in Lincoln, Nebraska. The experiment involves The Money Service (TMS), a franchised system developed by the staff of the First Federal Savings and Loan Association of Lincoln. Basically, TMS provides financial services for First Federal's customers through remote computer terminals at customer service counters in Hinky-Dinky supermarkets, permitting cardholders to complete transactions on their interest-bearing accounts at the savings and loan association and to cash checks. The system has received excellent consumer support and has increased the dollar and depositor saving's base of First Federal. The system is now being nationally marketed and has been expanded to include other financial institutions.

In a detailed review of point-of-sale systems, the Payment Systems Research Program pinpointed the value of TMS operations for individuals using that system. Among the factors that were identified as positive, tangible values to individual participants were:

ease of making deposits and withdrawals at more convenient locations;

expansion of financial transaction hours

safety of debit card as opposed to passbookthere is no way for unauthorized individuals to learn of the dollar balance of the account;

privacy -balances are not available to supermarket personnel; and

money on deposit earns interest until needed.

\section{Retailer Acceptance}

Several financial institutions have been able to successfully penetrate medium and small sized retailers with their funds transfer systems by offering to those retailers complementary internal control and management information systems they are unable to develop for themselves. Particularly active and successful in

7. Point of Sale, Project II, Payment Systems Research Program (New York: April 1974). 


\begin{abstract}
"Most large general merchandise retailers have adopted a wait-and-see attitude toward offering electronic funds transfer services at their points of sale. Their concern seems to be the lack of evidence of consumer demand for such service, and uncertainty regarding the impact it will have on their present credit accounts and on their own well-developed internal control and management information systems."
\end{abstract}

this development has been First National City Bank of New York, which has placed pointof-sale terminals in over 2,500 retail outlets. ${ }^{8}$

Most large general merchandise retailers have adopted a wait-and-see attitude toward offering electronic funds transfer services at their points of sale. Their concern seems to be the lack of evidence of consumer demand for such service, and uncertainty regarding the impact it will have on their present credit accounts and on their own well-developed internal control and management information systems.

Among food retailers there are those, such as the Jewell Company, that have developed integrated systems aimed at check clearance. Other food retailers are moving toward a more sophisticated internal system with the use of the Universal Product Code (UPC) in conjunction with electronic sensing devices at checkout stands. However, many food retailers are reluctant to plunge into electronic funds transfer services at the same time they are trying to educate customers about the changes brought on by use of the UPC.

The Project CABLE interviews with retailers, particularly supermarket operators, produced a consensus of the following needs those retailers want fulfilled in any EFTS operating at their points of sale.

$A$ role in the banking process. The retailer wants to be rewarded for the selling and servicing he performs for the financial institution.

Systematic planning and cost justification. This latter point may give rise to conflict with the need to operate dual systems, paper and electronic, for funds transfer into the future.

8. Cynthia Miller, Feb. 11, 1975.
Nondiscrimination. The retailer is interested in his customers, actual or potential, and these may not be synonymous with those who are customers of an individual financial institution.

Avoidance of depersonalization.

Differentiation from competitors.

Maintainence or increase of "front-end" productivity. This is one of the justifications for the electronic sensing and universal product code systems being developed for the grocery retail industry. The supermarket operator is in a labor intensive business and cannot afford a system that decreases that labor productivity.

Compatibility with the present internal system. The retailer wants an EFTS capable of delivering management information for decision-making.

These retailer needs identified in Project CABLE are consistent with the evaluation posed by the Payment Systems Research Program:

Financial institutions need to know a great deal more about retail objectives, requirements and systems plans... retailers need to understand why EFTS-POS, properly structured, would be to their benefit and to the benefit of their customers... a partnership is needed, not a buyer-seller relationship. 9

All of the needs outlined so far can be satisfied by the design of the transfer system. However, there is another potential impediment to retailer acceptance. Most have not operated in a regulatory climate and fear that implementing an EFTS will invite more government control than they now have.

\section{Financial Institution Acceptance}

The Independent Banker's Association of America, the small banks' trade association, has expressed anxiety over the future of the

9. Point of Sale, Project II, p. 3. 
small financial institution in an EFTS environment. However, the larger financial institutions are generally enthusiastic about electronic funds transfer. This enthusiasm stems from three potentialities: the possibility of skirting past legal restrictions, particularly impediments to geographic expansion; a means of consumer product diversification; and the ability to diversify into a related field.

The larger institutions have been spurred on by the general philosophy of the federal regulators-the Federal Home Loan Bank Board and the Administrator of National Banks. They are the principal proponents of the notion that regulation will follow, not lead, technology. The opponents are many of the individual state regulators. They fear the loss of state control over financial institutions and perceive that this is a move to effectively eliminate the dual financial institution system, state and national, that exists today. ${ }^{10}$ Thus, the state regulators lead the brigade of "regulation first, technological implementation second" and the federal regulators proclaim "full ahead, regulation will follow."

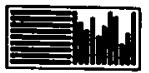

The Project CABLE research arrived at two major conclusions: teleshopping for goods is a concept removed from immediate implementation by retailers, and

10. Richard J. Francis, "EFTS-Progress Perspectives and Planning," an address before the Michigan Banker's Association Bank Management Conference, Dec. 3, 1974. electronic funds transfer systems are on the near horizon, but there is a question of the timing and nature of their evolutionary development.

A review of research literature shows no consistent evidence that consumers are ready to accept a total EFTS environment. The central issue is consumer readiness for change. That readiness has not yet been measured.

Much of the research effort to date has been devoted to studying the delivery system, which is not the key to understanding the problems and eventual construct of proposed marketing changes. The supplier, whether a financial institution or a merchant retailer, has to undertake a major reordering with it directly. Here lies the key to identifying some important policy issues.

If only large financial institutions and retailers are capable of reordering their internal systems, there are profound implications for the nation's antitrust policy. In the past, competition has often been enforced by localism, for example, by hometown protection of banking. There are moves on the state and national level to reverse these constrictions on competition, by such means as deregulating automatic teller machines as branch banks. If successful, these moves will have immense impact on the nature and structure of competition among suppliers of financial and retail services. 